\title{
KÊT QUẢ XỬ LÝ BƯỚC ĐẦU SỐ LIỂU ĐO SÂU TỪ TELUA TUYÊN HÒA BİNH - THÁ̉ NGUYÊN VÀ TUYẾN THANH HÓA - HÀ TÂY
}

\author{
LÊ HUY MINH ${ }^{1}$, ĐINH VĂN TOÀN ${ }^{2}$, VÕ THANH SƠN ${ }^{1}$, \\ NGUYẼ̃N CHIẾN THẮNG ${ }^{1}$, NGUYÊN BÁ DUẨ ${ }^{1}$, NGUYẼ̃ HÀ THÀNH $^{1}$, \\ LÊ TRUỠNG THANH ${ }^{1}$, GUY MARQUIS ${ }^{3}$ \\ E-mail: lhminhigp@gmail.com \\ ${ }^{1}$ Viện vật lý địa cầu, Viện $K H \& C N V N$ \\ ${ }^{2}$ Viện Địa chất, Viện $K H \& C N V N$ \\ ${ }^{3}$ Viện Vật lý Địa cầu Strasbourg, Cộng hòa Pháp
}

Ngày nhận bài: 20-4-2010

\section{Mở đầu}

Đới đứt gãy Sông Hồng là một trong những đới đứt gãy có khả năng phát sinh động đất mạnh trên lãnh thổ miền Bắc Việt Nam và Biển Đông. Đứt gãy kéo dài hơn $1000 \mathrm{~km}$ từ Tibet đến vịnh Bắc bộ là ranh giới phân chia giữa khối lục địa Nam Trung Hoa và khối Đông Dương. Nó là đối tượng nghiên cứu có ý nghĩa đặc biệt quan trọng đối với nhiều lĩnh vực khoa học và thực tế, đặc biệt là địa động lực thạch quyển khu vực Đông Nam Á, và vì thế từ trước đến nay đã có khá nhiều công trình nghiên cứu về cấu trúc sâu đới đứt gãy này bằng phương pháp đo sâu từ telua $[1,12]$ của các tác giả trong và ngoài nước $[6,9,10]$. Trong khuôn khổ đề tài độc lập cấp Nhà nước "Nghiên cưu cấu trúc sâu thạch quyển miền Bắc Việt Nam bằng dò sâu địa chấn và tù telua nhằm nâng cao độ tin câyy của các dụ báo thiên tai địa chất" hai tuyến đo sâu từ telua Hòa Bình - Thái Nguyên (TX Hòa Bình - Võ Nhai, Thái Nguyên) và Thanh Hóa - Hà Tây (Như Xuân, Thanh Hóa - Mỹ Đức, Hà Tây) đã được thực hiện. Trên hai tuyến đo cũng đồng thời tiến hành đo địa chấn dò sâu nhằm xác định một cách tin cậy các mặt ranh giới chính trong vỏ Trái Đất như ranh giới vỏ trên - vỏ giữa, ranh giới vỏ giữa vỏ dưới và ranh giới vỏ dưới - Manti (mặt Moho). Bài báo này trình bày phân tích bước đầu các kết quả đo sâu từ telua ở hai tuyến trên và kết quả minh giải về cấu trúc điện trở của các lớp trong vỏ Trái Đất.

\section{Thực địa đo sâu từ telua tuyến Hòa Bình - Thái Nguyên và Thanh Hóa - Hà Tây}

Thiết bị dùng để đo đạc là trạm đo sâu từ tellua Géo-Instrument của Viện Vật lý Địa cầu Paris viện trợ cho Viện Vật lý Địa cầu, đây là trạm đo sâu từtellua hiện đại ghi số duy nhất ở Việt Nam hiện nay. Thiết bị gồm: trạm đo trung tâm, máy tính, các điện cực, các cảm biến từ, dây nối các điện cực,... Các điện cực sử dụng trong đo sâu từ telua là các điện cực không phân cực có thế tiếp xúc rất nhỏ (một vài $\mathrm{mV}$ ) và độ trôi rất yếu. Các đầu thu từ được sử dụng là đầu thu kiểu cảm ứng có độ nhạy cỡ $10^{-2} \mathrm{nT}$, dây nối từ đầu thu từ tới máy ghi là $50 \mathrm{~m}$, đảm bảo tránh được các nguồn nhiê̂u từ nhỏ ở gần vị trí đặt trạm ghi. Các đầu thu từ này là loại đầu thu được sản xuất tại Trung tâm Địa vật lý tại Garcy, Cộng hòa Pháp.

Trên tuyến đo sâu từ telua Hòa Bình - Thái Nguyên (HB-TN) chúng tôi đã tiến hành đo đạc được 33 điểm đo và tuyến Thanh Hóa - Hà Tây (TH-HT) đo được 31 điểm. Độ dài của tuyến HB$\mathrm{TN}$ khoảng $122 \mathrm{~km}$, khoảng cách giữa các điểm đo trung bình là $4,35 \mathrm{~km}$, độ dài tuyến TH-HT khoảng $128,9 \mathrm{~km}$, với khoảng cách đểm đo trung bình là $4,16 \mathrm{~km}$. Tọa độ và tên từng điểm đo được liệt kê trong bảng 1 và được biểu diễn trên hình 1 . Tại từng điểm đo sâu chúng tôi tiến hành đo đạc hai thành phần trường điện và hai thành phần 
trường từ theo hai hướng vuông góc với nhau một cách tương ứng; một hướng được chọn song song với phương cấu trúc $\left(\mathrm{N} 140^{\circ}\right)$ được gọi là thành phần NS và một hướng được chọn vuông góc với phương cấu trúc $\left(\mathrm{N} 50^{\circ}\right)$ được gọi là thành phần EW.

Bảng 1. Tọa độ các điểm đo sâu từ telua tuyến Hòa Bình - Thái Nguyên và tuyến Thanh Hóa - Hà Tây

\begin{tabular}{|c|c|c|c|c|}
\hline \multirow[b]{2}{*}{ Điểm } & \multicolumn{2}{|c|}{ Tọa độ } & \multirow{2}{*}{ Độ cao (m) } & \multirow{2}{*}{ Địa danh } \\
\hline & Vỹ độ & Kinh độ & & \\
\hline \multicolumn{5}{|c|}{ Tuyến Hòa Bình - Thái Nguyên } \\
\hline N01 & $21^{\circ} 42^{\prime} 55,38^{\prime \prime}$ & $105^{\circ} 55^{\prime} 53,16^{\prime \prime}$ & 40 & Đồng Chùa, La Hiên, Võ Nhai, Thái Nguyên \\
\hline N02 & $21^{\circ} 41^{\prime} 14,28^{\prime \prime}$ & $105^{\circ} 55^{\prime} 29,10^{\prime \prime}$ & 45 & Đèo Khế, Khe Mo, Đồng Hỷ, Thái Nguyên \\
\hline N03 & $21^{\circ} 40^{\prime} 0,96^{\prime \prime}$ & $105^{\circ} 53^{\prime} 12,78^{\prime \prime}$ & 40 & Khe Mo, Đồng Hỷ, Thái Nguyên \\
\hline N04 & $21^{\circ} 37^{\prime} 0,88^{\prime \prime}$ & $105^{\circ} 52 ’ 24,84^{\prime \prime}$ & 40 & Cây Thị, Linh Sơn, Đồng Hỷ, Thái Nguyên \\
\hline N05 & $21^{\circ} 32^{\prime} 40,02^{\prime \prime}$ & $105^{\circ} 47^{\prime} 50,04^{\prime \prime}$ & 35 & Nhà Thờ, Thịnh Đức, Tp. Thái Nguyên \\
\hline N06 & $21^{\circ} 29^{\prime} 54,24^{\prime \prime}$ & $105^{\circ} 48^{\prime} 33,54^{\prime \prime}$ & 25 & Xuân Đảng, Bình Sơn, Sông Công, Thái Nguyên \\
\hline N07 & $21^{\circ} 27^{\prime} 12,06^{\prime \prime}$ & $105^{\circ} 45^{\prime} 32,58^{\prime \prime}$ & 30 & Xóm Chêng, Phúc Thuận, Phổ Yên, Thái Nguyên \\
\hline N08 & $21^{\circ} 24^{\prime} 15,30^{\prime \prime}$ & $105^{\circ} 44^{\prime} 52,38^{\prime \prime}$ & 75 & Ngọc Thanh, Tx. Xuân Hòa, Vĩnh Phú \\
\hline N09 & $21^{\circ} 20^{\prime} 0,60^{\prime \prime}$ & $105^{\circ} 42^{\prime} 05,76^{\prime \prime}$ & 10 & Vĩnh Đồng, Trung Mỹ, Bình Xuyên, Hà Tây \\
\hline N10 & $21^{\circ} 19^{\prime} 40,32 \prime$ & $105^{\circ} 41^{\prime} 50,46^{\prime \prime}$ & 20 & Vĩnh Tiến, Bá Hiến, Bình Xuyên, Vĩnh Phú \\
\hline N11 & $21^{\circ} 17^{\prime} 24,72^{\prime \prime}$ & $105^{\circ} 39^{\prime} 39,90^{\prime \prime}$ & 10 & Nội Phật, Tam Hợp, Bình Xuyên, Vĩnh Phú \\
\hline N12 & $21^{\circ} 14^{\prime} 59,94^{\prime \prime}$ & $105^{\circ} 37^{\prime} 31,62^{\prime \prime}$ & 5 & Xuân Lãng, Thanh Lãng, Bình Xuyên, Vĩnh Phú \\
\hline N13 & $21^{\circ} 12^{\prime} 40,44^{\prime \prime}$ & $105^{\circ} 33^{\prime} 32,94^{\prime \prime}$ & 7 & Xóm Lẻ, Tam Hồng, Yên Lạc, Vĩnh Phú \\
\hline N14 & $21^{\circ} 09^{\prime} 44,94 \prime$ & $105^{\circ} 33^{\prime} 22,92^{\prime \prime}$ & 6 & Nhật Chiêu, Liên Châu, Yên Lac, Vĩnh Phú \\
\hline N15 & $21^{\circ} 08^{\prime} 22,08^{\prime \prime}$ & $105^{\circ} 33^{\prime} 53,10^{\prime \prime}$ & 6 & Xóm Tám, Võng Xuyên, Phúc Thọ, Hà Tây \\
\hline N16 & $21^{\circ} 07^{\prime} 39,60^{\prime \prime}$ & $105^{\circ} 33^{\prime} 21,18^{\prime \prime}$ & 7 & Lạc Xuyên, Võng Xuyên, Phúc Thọ, Hà Tây \\
\hline N17 & $21^{\circ} 04^{\prime} 54,48^{\prime \prime}$ & $105^{\circ} 32^{\prime} 30,00^{\prime \prime}$ & 8 & Yên Lỗ, Cẩm Yên,Thạch Thất, Hà Tây \\
\hline N18 & $21^{\circ} 04^{\prime} 09,54^{\prime \prime}$ & $105^{\circ} 29^{\prime} 34,50^{\prime \prime}$ & 15 & Thiên Mã, Sơn Đông, Phúc Thọ, Hà Tây \\
\hline N19 & $21^{\circ} 02^{\prime} 11,46^{\prime \prime}$ & $105^{\circ} 28^{\prime} 40,08^{\prime \prime}$ & 23 & Đồng Mô, Hà Tây \\
\hline N20 & $20^{\circ} 59^{\prime} 10,20^{\prime \prime}$ & $105^{\circ} 25^{\prime} 00,06^{\prime \prime}$ & 85 & Xóm Mè, Yên Quang, Lương Sơn, Hòa Bình \\
\hline N21 & $21^{\circ} 00^{\prime} 25,98^{\prime \prime}$ & $105^{\circ} 26^{\prime} 42,30^{\prime \prime}$ & 36 & Đồng Tới, Yên Trung, Lương Sơn, Hòa Bình \\
\hline N22 & $20^{\circ} 54^{\prime} 47,04^{\prime \prime}$ & $105^{\circ} 23^{\prime} 13,86^{\prime \prime}$ & 71 & Xóm Bân, Phúc Tiến, Lương Sơn, Hòa Bình \\
\hline N23 & $20^{\circ} 53^{\prime} 40,20^{\prime \prime}$ & $105^{\circ} 23^{\prime} 25,74^{\prime \prime}$ & 42 & Xóm Mỏ, Dân Hạ, Kỳ Sơn, Hòa Bình \\
\hline N24 & $20^{\circ} 45^{\prime} 47,58^{\prime \prime}$ & $105^{\circ} 20^{\prime} 50,04^{\prime \prime}$ & 110 & Đồng Chua, Thống Nhất, thị xã HB, Hòa Bình \\
\hline N25 & $20^{\circ} 47^{\prime} 47,88^{\prime \prime}$ & $105^{\circ} 21 ' 21,06 ”$ & 25 & Bái Yên, Dân Chủ, Tp. Hòa Bình, Hòa Bình \\
\hline L14 & $21^{\circ} 09^{\prime} 49,44^{\prime \prime}$ & $105^{\circ} 33^{\prime} 31,44^{\prime \prime}$ & 10 & Cựu Ấp, Liên Châu, Yên Lạc, Vĩnh Phúc \\
\hline N27 & $21^{\circ} 20^{\prime} 15,12^{\prime \prime}$ & $105^{\circ} 42^{\prime} 00,60^{\prime \prime}$ & 7 & Vĩnh Đông, Bá Hiến, Bình Xuyên, Vĩnh Phúc \\
\hline N28 & $21^{\circ} 19^{\prime} 38,22^{\prime \prime}$ & $105^{\circ} 41^{\prime} 54,78^{\prime \prime}$ & 19 & Vinh Tiến, Bá Hiến, Bình Xuyên, Vĩnh Phúc \\
\hline N29 & $21^{\circ} 24^{\prime} 46,8^{\prime \prime}$ & $105^{\circ} 44^{\prime} 50,58^{\prime \prime}$ & 70 & Ngọc Thanh, TX Xuân Hòa, Vĩnh Phúc \\
\hline N30 & $21^{\circ} 17^{\prime} 16,62 \prime$ & $105^{\circ} 39^{\prime} 39,96^{\prime \prime}$ & 8 & Nội Phật, Tam Hợp, Bình Xuyên, Vĩnh Phúc \\
\hline N31 & $21^{\circ} 14^{\prime} 5,34^{\prime \prime}$ & $105^{\circ} 35^{\prime} 29,16^{\prime \prime}$ & 7 & Đông Thôn, Tam Hồng, Yên Lạc, Vĩnh Phúc \\
\hline N32 & $21^{\circ} 21^{\prime} 4,8^{\prime \prime}$ & $105^{\circ} 42^{\prime} 18,36^{\prime \prime}$ & 20 & Vĩnh Đông, Trung Mỹ, Bình Xuyên, Vĩnh Phúc \\
\hline N33 & $21^{\circ} 14^{\prime} 48,42^{\prime \prime}$ & $105^{\circ} 37^{\prime} 20,22 \prime$ & 2 & Yên Lân, Thanh Lãng, Bình Xuyên, Vĩnh Phúc \\
\hline \multicolumn{5}{|c|}{ Tuyến Như Xuân, Thanh Hóa - Mỹ Đức, Hà Tây } \\
\hline T01 & $19^{\circ} 28^{\prime} 14,34^{\prime \prime}$ & $105^{\circ} 24 ’ 21,54^{\prime \prime}$ & 143 & Đội 6, Bãi Trành, Như Xuân, Thanh Hóa \\
\hline T02 & $19^{\circ} 31^{\prime} 28,32$ ' & $105^{\circ} 24^{\prime} 9,72^{\prime \prime}$ & 122 & Xuân Hòa, Như Xuân, Thanh Hóa \\
\hline T03 & $19^{\circ} 33^{\prime} 39,42^{\prime \prime}$ & $105^{\circ} 23 ’ 3,12 "$ & 96 & Xuân Hòa, Như Xuân, Thanh Hóa \\
\hline T04 & $19^{\circ} 37^{\prime} 10,92 "$ & $105^{\circ} 22 ’ 36,66^{\prime \prime}$ & 113 & Thanh Hương, Xuân Quý, Như Xuân, Thanh Hóa \\
\hline T05 & $19^{\circ} 38^{\prime} 28,74^{\prime \prime}$ & $105^{\circ} 23^{\prime} 56,82^{\prime \prime}$ & 106 & Tân Thịnh, Hóa Quỳ, Như Xuân, Thanh Hóa \\
\hline T06 & $19^{\circ} 41^{\prime} 55,44^{\prime \prime}$ & $105^{\circ} 27^{\prime} 21,66^{\prime \prime}$ & 64 & Thanh Hóa \\
\hline T07 & $19^{\circ} 51^{\prime} 19,68 \prime$ & $105^{\circ} 24 ’ 39,42^{\prime \prime}$ & 60 & Làng Bài, Xuân Phú, Thọ Xuân, Thanh Hóa \\
\hline
\end{tabular}


Bảng 1 (tiếp theo)

\begin{tabular}{|c|c|c|c|c|}
\hline T08 & $19^{\circ} 42^{\prime} 9,48^{\prime \prime}$ & $105^{\circ} 27^{\prime} 47,88^{\prime \prime}$ & 53 & Thượng Vinh, Như Xuân, Thanh Hóa \\
\hline T09 & $19^{\circ} 44^{\prime} 49,62^{\prime \prime}$ & $105^{\circ} 25^{\prime} 48,42^{\prime \prime}$ & 38 & Thượng Ninh, Như Xuân, Thanh Hóa \\
\hline T10 & $19^{\circ} 48^{\prime} 17,28^{\prime \prime}$ & $105^{\circ} 22^{\prime} 53,52 "$ & 35 & Liêm Thanh, Luận Thành, Thường Xuân, Thanh Hóa \\
\hline T11 & $19^{\circ} 55^{\prime} 22,62 ”$ & $105^{\circ} 22^{\prime} 42,60^{\prime \prime}$ & 20 & Bái Đô, Xuân Bái, Thường Xuân, Thanh Hóa \\
\hline T12 & $19^{\circ} 58^{\prime} 1,02^{\prime \prime}$ & $105^{\circ} 24^{\prime} 45,12^{\prime \prime}$ & 31 & Thành Công, Kiến Thọ, Ngọc Lặc, Thanh Hóa \\
\hline $\mathrm{T} 13$ & $20^{\circ} 08^{\prime} 12,42^{\prime \prime}$ & $105^{\circ} 24^{\prime} 17,52^{\prime \prime}$ & 91 & Quang Tọa, Quang Trung, Ngọc Lặc, Thanh Hóa. \\
\hline T14 & $20^{\circ} 09^{\prime} 33,9^{\prime \prime}$ & $105^{\circ} 26^{\prime} 40,44^{\prime \prime}$ & 96 & Làng Quần, Cẩm Châu, Cẩm Thủy, Thanh Hóa \\
\hline T15 & $20^{\circ} 11^{\prime} 15,60^{\prime \prime}$ & $105^{\circ} 28^{\prime} 3,78^{\prime \prime}$ & 40 & Làng Lụa, Cẩm Sơn, Cẩm Thủy, Thanh Hóa \\
\hline T16 & $20^{\circ} 18^{\prime} 8,46^{\prime \prime}$ & $105^{\circ} 30^{\prime} 39,66^{\prime \prime}$ & 30 & Nàng Trường, Thạch Quảng, Thạch Thành, Thanh Hóa \\
\hline T17 & $20^{\circ} 17^{\prime} 44,94^{\prime \prime}$ & $105^{\circ} 30^{\prime} 30,3^{\prime \prime}$ & 20 & Thống Nhất, Thạch Tượng, Thạch Thành, Thanh Hóa \\
\hline T18 & $20^{\circ} 13^{\prime} 23,94^{\prime \prime}$ & $105^{\circ} 28^{\prime} 40,92 "$ & 21 & Ngọc Liêm, Cẩm Tú, Cẩm Thủy, Thanh Hóa \\
\hline T19 & $20^{\circ} 15^{\prime} 34,62 \prime$ & $105^{\circ} 30^{\prime} 14,94^{\prime \prime}$ & 115 & Đồi Mã, Cẩm Tú, Cẩm Thủy, Thanh Hóa \\
\hline T20 & $20^{\circ} 24^{\prime} 58,56^{\prime \prime}$ & $105^{\circ} 30^{\prime} 10,56^{\prime \prime}$ & 30 & Xuân Lão, An Nghĩa, Lạc Sơn, Hòa Bình \\
\hline T21 & $20^{\circ} 24^{\prime} 22,14^{\prime \prime}$ & $105^{\circ} 35^{\prime} 46,26^{\prime \prime}$ & 60 & Di Dân, Yên Lạc, Yên Thủy, Hòa Bình \\
\hline T22 & $20^{\circ} 26^{\prime} 23,94^{\prime \prime}$ & $105^{\circ} 36^{\prime} 59,7^{\prime \prime}$ & 37 & Bĩa Đa, Bảo Hiệu, Yên Thủy, Hòa Bình \\
\hline $\mathrm{T} 23$ & $20^{\circ} 27^{\prime} 13,62 \prime$ & $105^{\circ} 38^{\prime} 34,68^{\prime \prime}$ & 45 & Bãi Cá, Bảo Hiệu, Yên Thủy, Hòa Bình \\
\hline T24 & $20^{\circ} 32^{\prime} 43,32^{\prime \prime}$ & $105^{\circ} 42^{\prime} 10,68^{\prime \prime}$ & 40 & Hưng Thị, Lạc Thủy, Hòa Bình \\
\hline T25 & $20^{\circ} 35^{\prime} 57,6^{\prime \prime}$ & $105^{\circ} 43^{\prime} 35,04^{\prime \prime}$ & 10 & An Phú, Mỹ Đức, Hà Tây \\
\hline T26 & $20^{\circ} 05^{\prime} 21,18^{\prime \prime}$ & $105^{\circ} 24^{\prime} 21,24^{\prime \prime}$ & 60 & Điền Sơn, Ngọc Sơn, Ngọc Lặc, Thanh Hóa \\
\hline T27 & $20^{\circ} 03^{\prime} 05,28^{\prime \prime}$ & $105^{\circ} 26^{\prime} 9,42^{\prime \prime}$ & 21 & Ngọc Trung, Ngọc Lặc, Thanh Hóa \\
\hline T28 & $20^{\circ} 00^{\prime} 2,52 \prime$ & $105^{\circ} 24^{\prime} 41,04^{\prime \prime}$ & 25 & Minh Tiến, Ngọc Lặc, Thanh Hóa \\
\hline T29 & $20^{\circ} 14^{\prime} 58,44^{\prime \prime}$ & $105^{\circ} 30^{\prime} 9,54^{\prime \prime}$ & 50 & Lương Thành, Cẩm Tú, Cẩm Thủy, Thanh Hóa \\
\hline T30 & $20^{\circ} 28^{\prime} 41,58^{\prime \prime}$ & $105^{\circ} 40^{\prime} 412,22 "$ & 40 & Đồng Bai, Lạc Hưng, Lạc Thủy, Hòa Bình \\
\hline T31 & $20^{\circ} 31^{\prime} 20,52 \prime$ & $105^{\circ} 40^{\prime} 41,52^{\prime \prime}$ & 25 & Suối Mán, Hưng Thị, Lạc Thủy, Hòa Bình \\
\hline
\end{tabular}

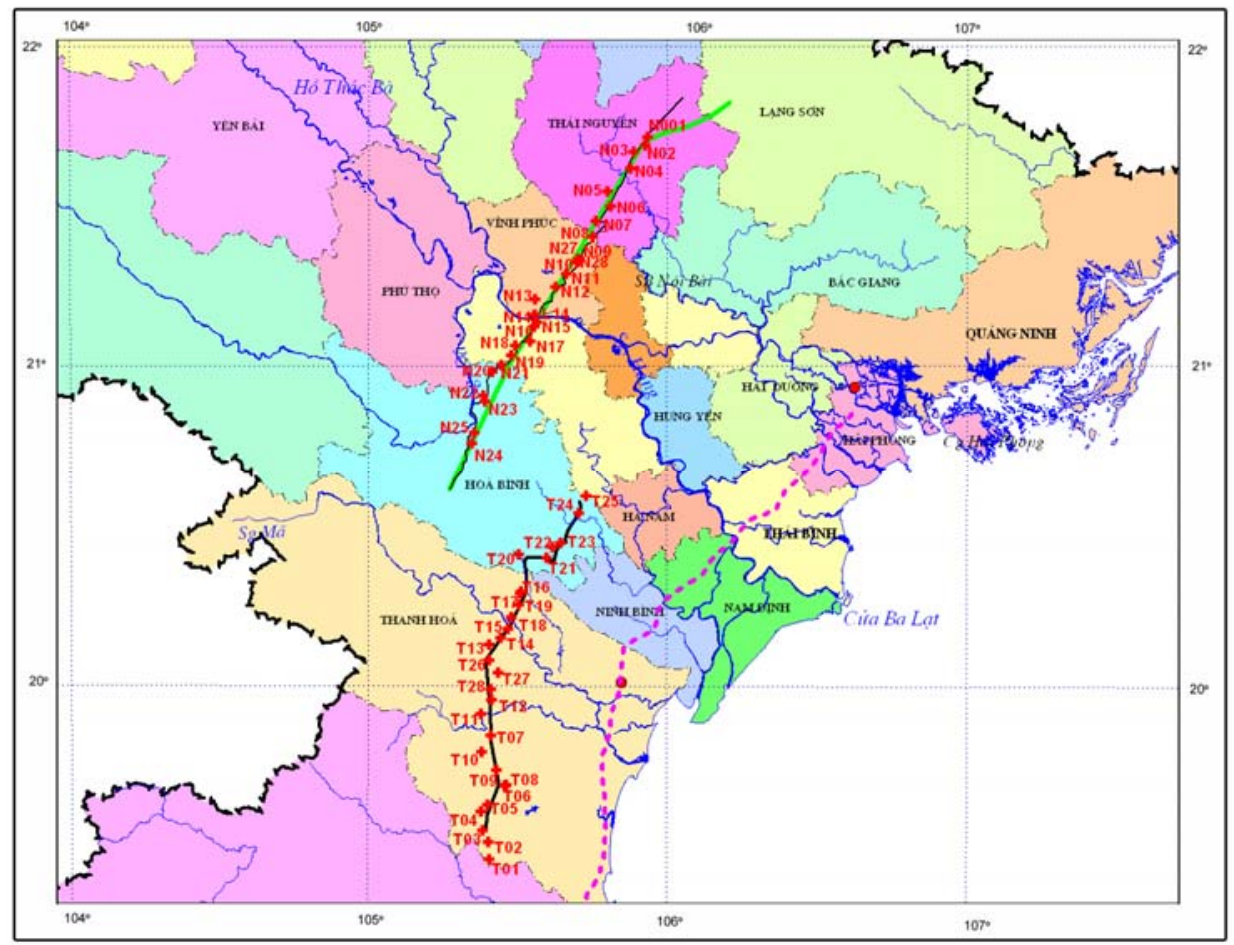

Hình 1. Sơ đồ các tuyến đo sâu từ telua Hòa Bình - Thái Nguyên và Như Xuân, Thanh Hóa - Mỹ Đức, Hà Tây 


\section{Xử lý số liệu đo sâu từ telua}

Dựa trên các chuỗi số liệu các thành phần trường điện và trường từ thu được chúng tôi tiến hành xử lý bằng phần mềm MT [6], một phần mềm đi kèm hệ thống thiết bị Géo-Instrument để thu được các đường cong điện trở suất biểu kiến theo hai hướng $\mathrm{NS}$ và $\mathrm{EW}$ như đã nêu, việc xử lý bằng phần mềm này đòi hỏi 8 bloc số liệu liên tiếp có chất lượng tốt. Hình 2 là ví dụ các đường cong đo sâu thành phần NS (các điểm tròn) và thành phần EW (các điểm hình thoi) thu được tại điểm L14. Tập hợp các đường cong đo sâu thu được tại tất cả các điểm đo là cơ sở cho các phép nghịch đảo $1 \mathrm{D}$ và $2 \mathrm{D}$ xây dựng các mặt cắt cấu trúc địa điện vỏ Trái Đất trên tuyến nghiên cứu.

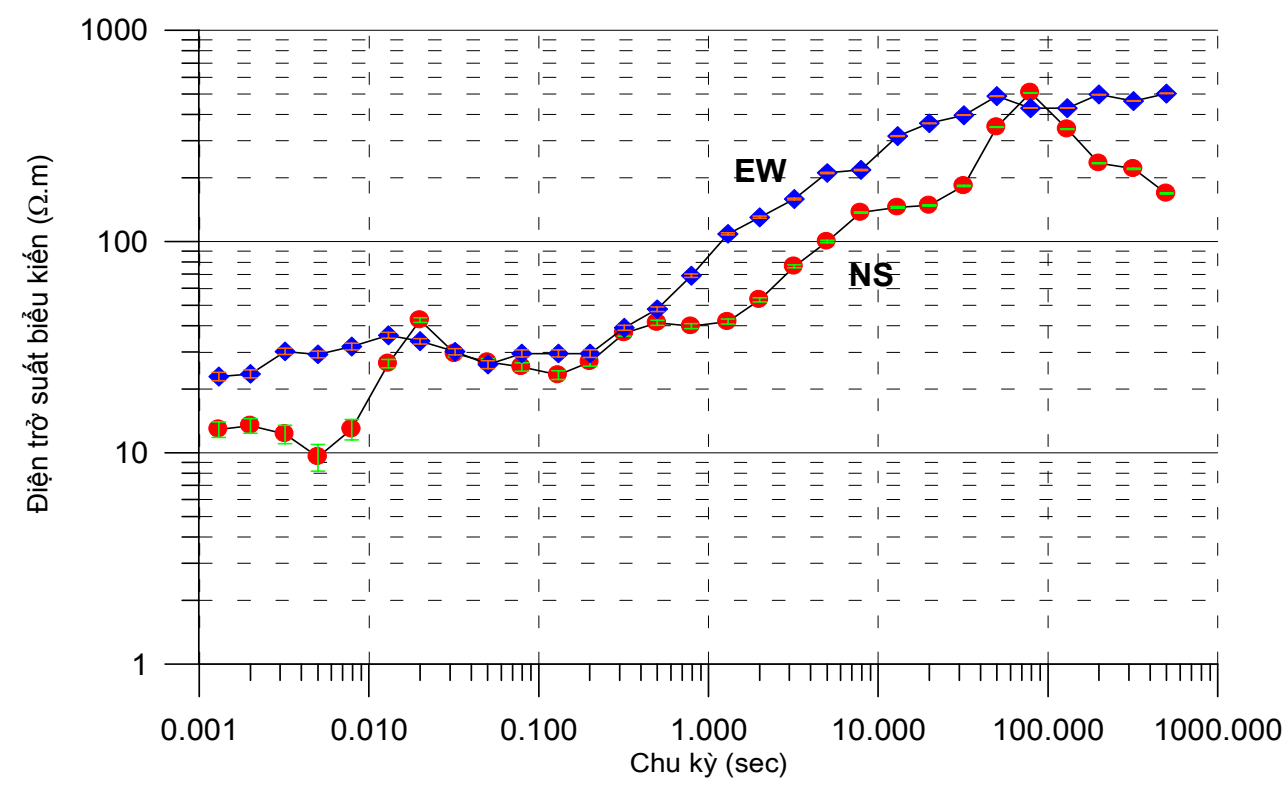

Hinh 2. Các đường cong đo sâu từ telua thành phần NS (các điểm tròn) và thành phần EW (các điểm hình thoi) tại điểm L14 tuyến Hòa Bình - Thái Nguyên

\section{Biểu diễn giả mặt cắt điện trở suất biểu kiến}

Để có được ý niệm sơ bộ về cấu trúc điện trở suất trên toàn tuyến đo chúng tôi xây dựng các giả mặt cắt điện trở suất biểu kiến, trục hoành là khoảng cách giữa các điểm đo đạc, trục tung là tần số đo đạc được vẽ ở tỷ lệ logarit. Hình 3 là giả mặt cắt điện trở suất biểu kiến đối với thành phần $\mathrm{EW}$, hình 4 là giả mặt cắt điện trở suất biểu kiến đối với thành phần NS đối với tuyến HB-TN. Chúng ta biết rằng tần số sóng điện từ càng cao (chu kỳ càng ngắn) độ sâu thâm nhập càng nông, tần số càng thấp (chu kỳ càng dài) độ sâu thâm nhập càng lớn, do đó giả mặt cắt có thể cho chúng ta ý niệm sơ bộ về cấu trúc vỏ Trái Đất trên tuyến nghiên cứu. Trên tuyến có những điểm có điện trở suất thấp hơn so với các điểm xung quanh, ví dụ các điểm N04, N08, N13-L14, N18,... Chúng ta biết rằng ở các đới đứt gãy, đá trong vỏ bị dập vỡ do đó điện trở suất tại điểm đứt gãy điện trở suất thường nhỏ hơn so với điểm xung quanh $[4,5,10,11]$. Như thế so với các dấu hiệu địa chất và địa vật lý khác có thể nhận định rằng điểm N04 gần đứt gãy Quốc Lộ 13, N08 gần đứt gãy Đông Triều-Uông Bí, điểm N13L14 gần đứt gãy sông Chảy, điểm N18 gần đứt gãy sông Hồng. Tuy nhiên hình thái cụ thể của các đứt gãy này chỉ có thể thu được trên cơ sở tiến hành các phép nghịch đảo $2 \mathrm{D}$ xây dựng các mặt cắt địa điện cấu trúc sâu vỏ Trái Đất ở tuyến nghiên cứu.

Mặt khác ở phần nhiều các điểm đo, vùng tần số trung bình điện trở suất biểu kiến cao hơn phần tần số thấp và tần số cao, điều đó cho chúng ta ý niệm rằng trong mô hình mặt cắt điện trở suất vỏ Trái Đất xây dựng được, phần giữa của mặt cắt sẽ có điện trở suất cao hơn phần trên cùng và phần dưới sâu. 


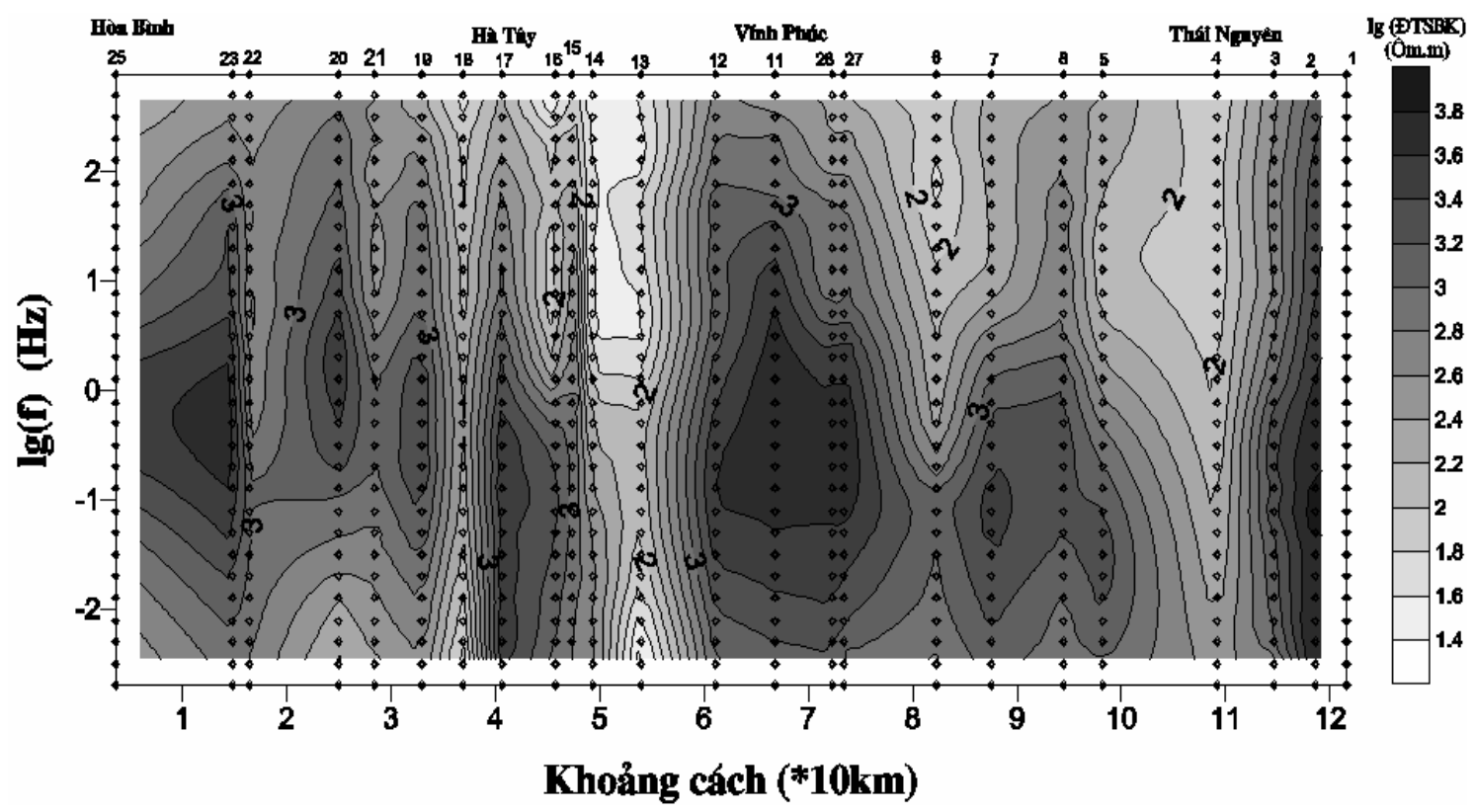

Hình 3. Giả mặt cắt điện trở suất biểu kiến thành phần EW tuyến Hòa Bình - Thái Nguyên

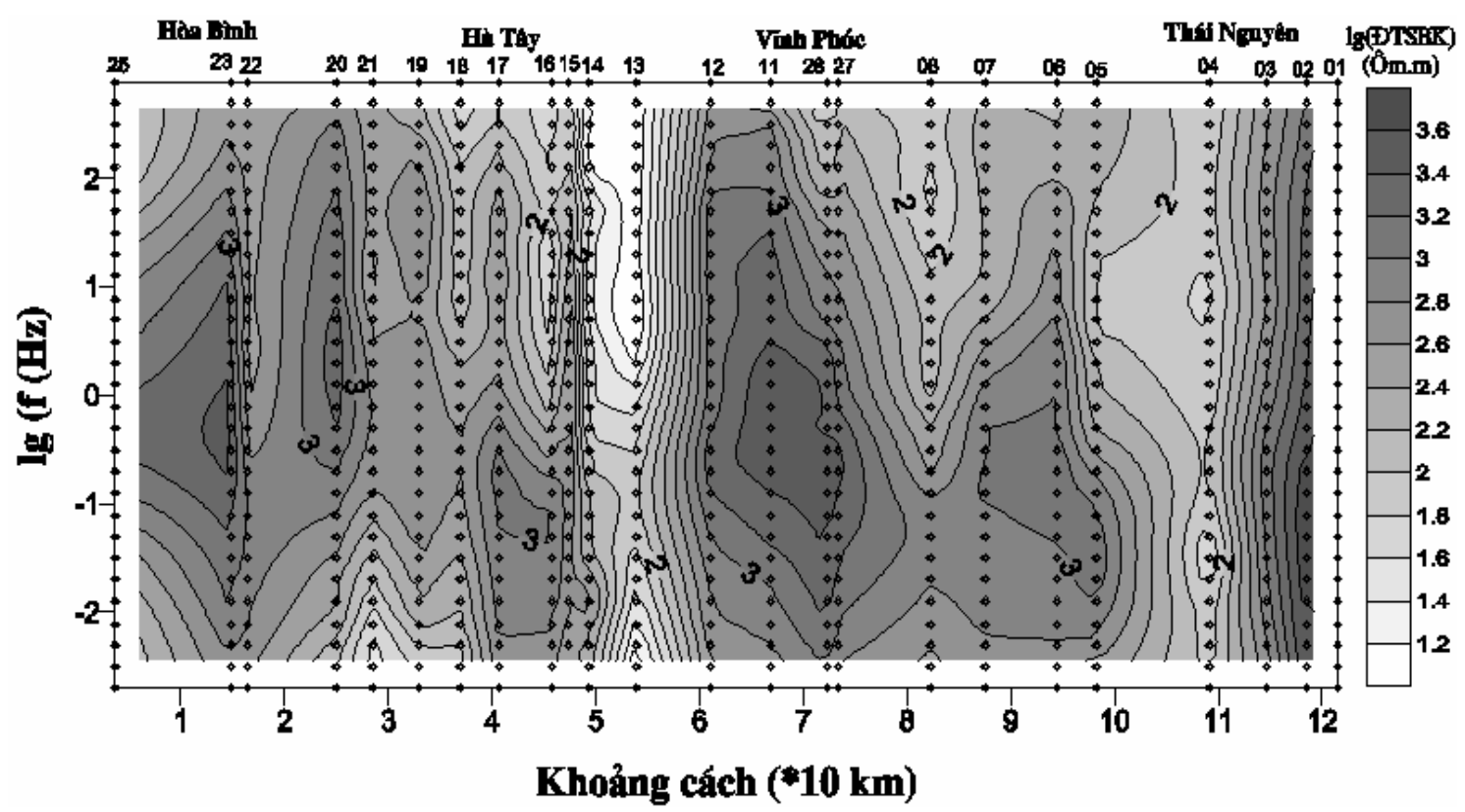

Hình 4. Giả mặt cắt điện trở suất biểu kiến thành phần NS, tuyến Hòa Bình - Thái Nguyên

Giả mặt cắt điện trở suất biểu kiến thành phần EW và thành phần NS tuyến NX-MĐ được trình bày trên hình 5 và hình 6 . Chúng ta có thể thấy rằng ở phần lớn các điểm trên tuyến phần tần số trung bình có điện trở suất cao hơn ở phần tần số cao và phần tần số thấp. Mô hình vỏ Trái Đất sẽ có ba lớp tiêu biểu với điện trở suất ở trên cùng của vỏ và lớp dưới cùng của vỏ có điện trở thấp so với lớp vỏ giữa. 


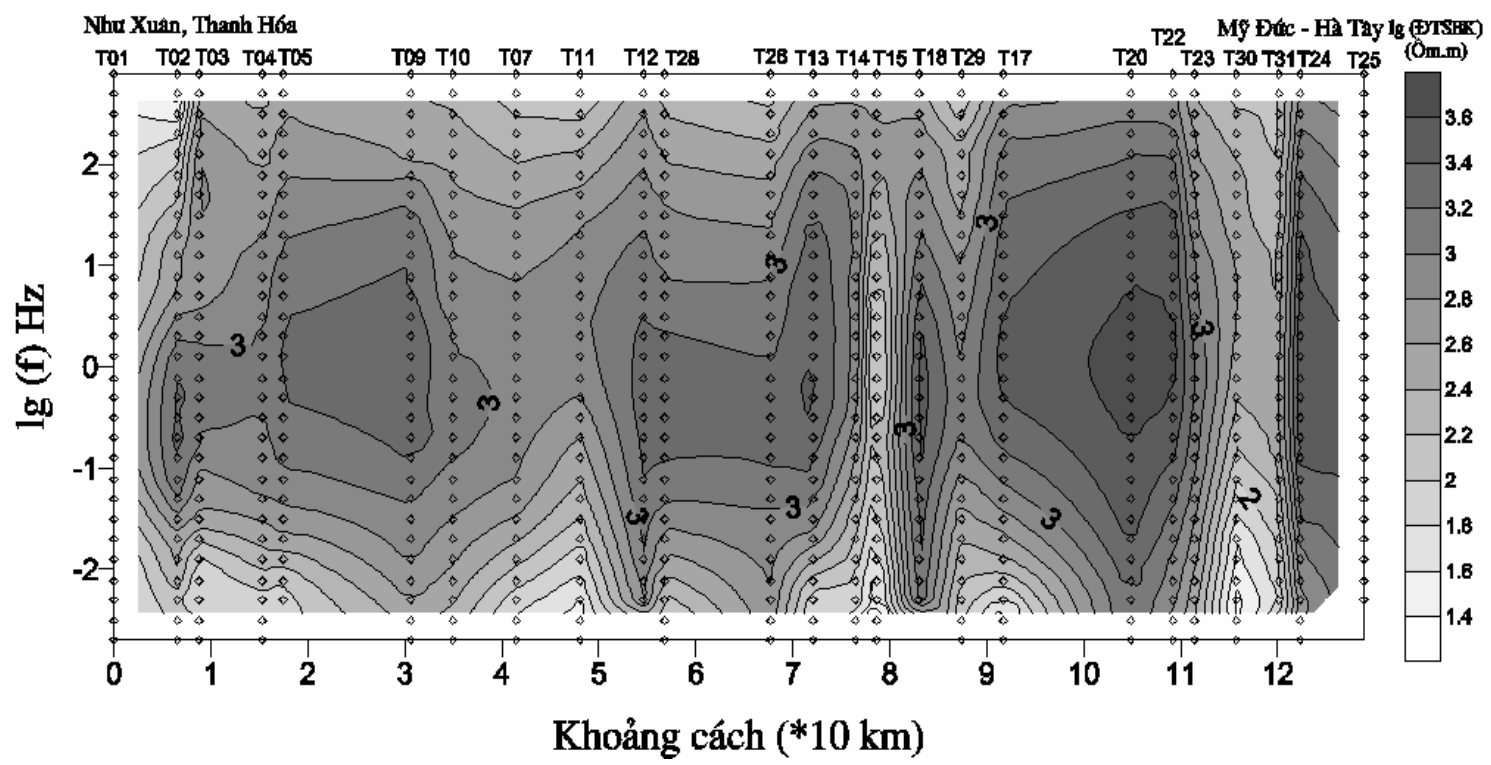

Hình 5. Giả mặt cắt điện trở suất biểu kiến thành phần EW tuyến Thanh Hóa - Hà Tây

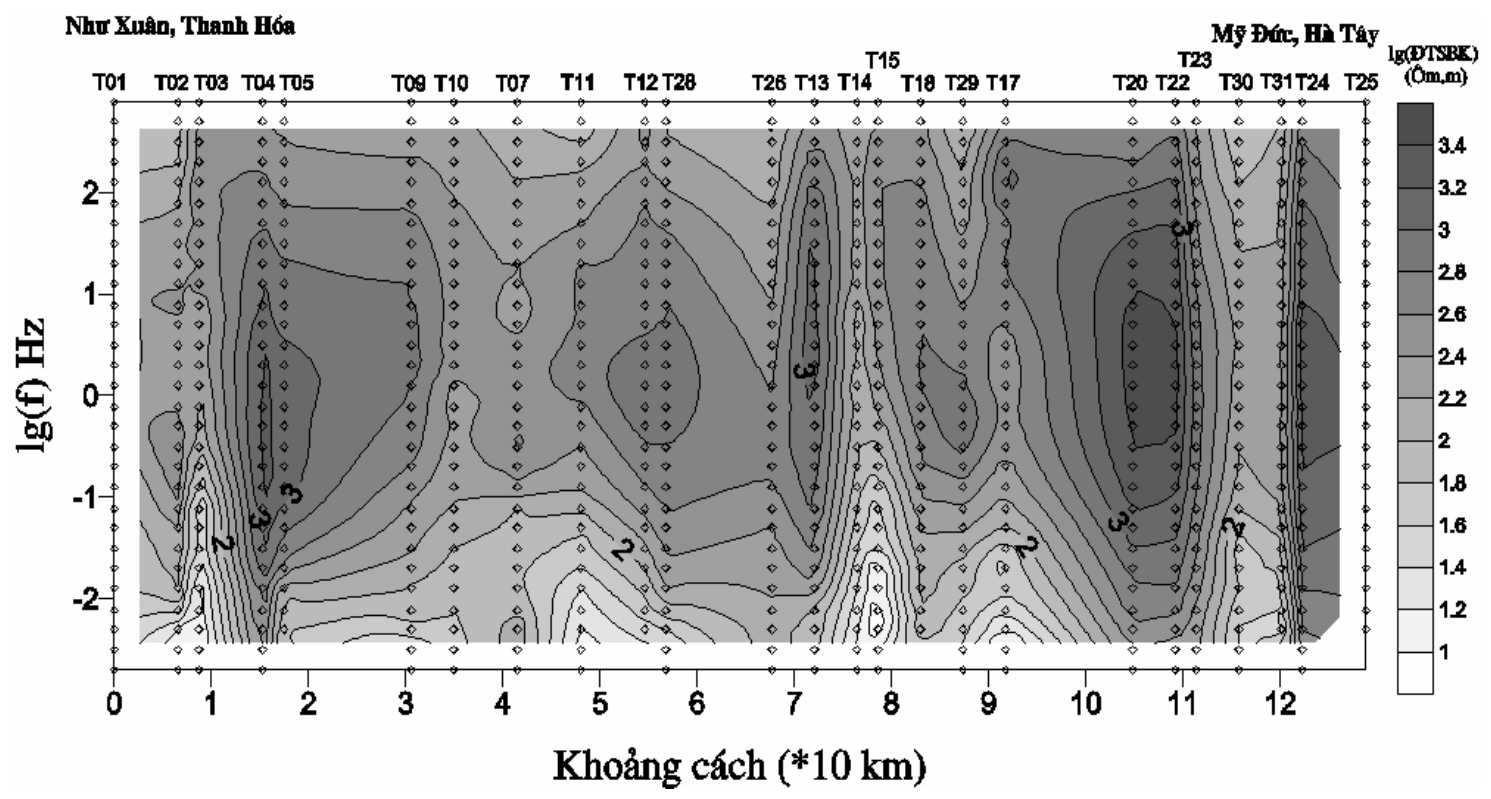

Hình 6. Giả mặt cắt điện trở suất biểu kiến thành phần NS tuyến Thanh Hóa - Hà Tây

\section{Kết qủa nghịch đảo số liệu và thảo luận}

Trước hết chúng tôi trình bày các kết quả nghịch đảo $2 \mathrm{D}$. Trong phép nghịch đảo $2 \mathrm{D}$ ta phải làm hợp đồng thời tất cả các đường cong điện trở suất bằng mô hình điện trở suất của môi trường bên dưới. Chính vì thế nên bằng phép nghịch đảo $2 \mathrm{D}$ có thể phát hiện được các bất đồng nhất theo phương nằm ngang, nhất là các đới đứt gãy, do vậy chúng tôi bắt đầu việc minh giải số liệu đo sâu từ telua bằng việc thực hiện phép nghịch đảo $2 \mathrm{D}$.
Chúng tôi sử dụng phép nghịch đảo $2 \mathrm{D}$ bằng phương pháp giảm dư nhanh (Rapid Relaxation Inverse-RRI) [8] thực hiện với phần mềm Geotools [2]. Phép nghịch đảo 2D RRI có thể được thực hiện riêng rẽ đối với từng thành phần, hoặc đồng thời cả hai thành phần. Trong phân tích $2 \mathrm{D}$ số liệu từ telua các tuyến HB-TN và TH-HT chúng tôi chọn mô hình ban đầu là nửa không gian đồng nhất có điện trở suất $100 \Omega$.m. Trong quá trình tính toán chúng tôi thấy rằng việc lựa chọn nghiệm $2 \mathrm{D}$ cho nghịch 
đảo cả hai thành phần NS và EW đối với các tuyến đo không cho kết quả hội tụ, mà chỉ chọn được nghiệm cho thành phần $\mathrm{EW}$ và kết quả được trình bày trên hình 7,8 . Các hình vẽ được xây dựng ở cùng tỷ lệ ngang và tỷ lệ đứng, trục hoành là chiều dài tuyến, trục tung là độ sâu. Từ thông tin địa chất tuyến Hòa Bình - Thái Nguyên cắt qua nhiều đứt gãy: đứt gãy sông Hồng, đứt gãy sông Chảy, đứt gãy sông Lô, đứt gãy Đông Triều - Uông Bí... và trên mặt cắt địa điện hình 7 chúng ta có thể nhận thấy biểu hiện của đứt gãy Mường La - Bắc Yên, đứt gãy sông Hồng, đứt gãy sông Chảy và đứt gãy sông Lô bằng các ranh giới thay đổi điện trở rõ rệt cắt qua toàn bộ vỏ Trái Đất. Các đới đứt gãy này như thế là các đứt gãy lớn xuyên vỏ, điều này phù hợp với các kết quả nghiên cứu trước đây. Đứt gãy Mường La - Bắc Yên có hướng cắm gần như thẳng đứng. Đứt gãy sông Hồng và đứt gãy sông Chảy có góc dốc khoảng $88^{\circ}$ nghiêng về phía đông bắc (tức là về phía cuối tuyến Thái Nguyên); đứt gãy sông Lô có góc dốc khoảng $92^{\circ}$ hướng về phía tây nam (phía Hòa Bình). Các kết quả này phù hợp với những kết quả nghiên cứu trước đây, nhất là các kết quả nghiên cứu địa chấn sâu ngoài biển. Khoảng cách giữa các điểm đo khá thưa nên có thể vị trí điểm đo không nằm trong đới phá hủy đứt gãy trên mặt cắt điện trở suất không thể hiện được, nhất là các đứt gãy nhỏ có đới phá hủy hẹp, chính vì thế các đứt gãy như đứt gãy Đông Triều - Uông Bí, đứt gãy Quốc lộ 134, đứt gãy Đèo Khế không phát hiện được.

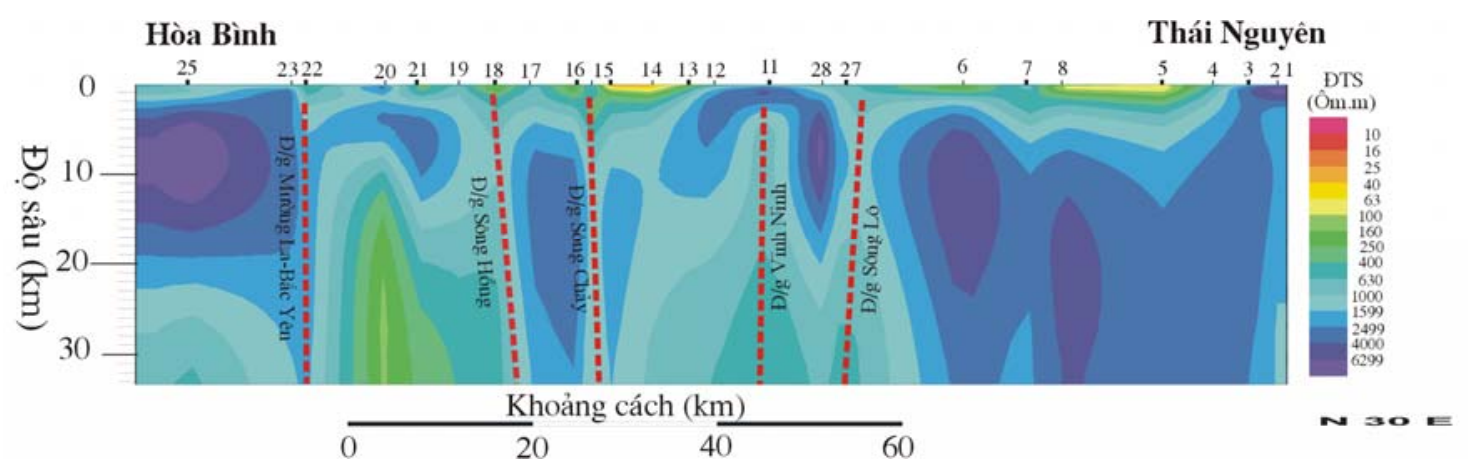

Hình 7. Mặt cắt địa điện tuyến Hòa Bình-Thái Nguyên, nghịch đảo 2D thành phần EW

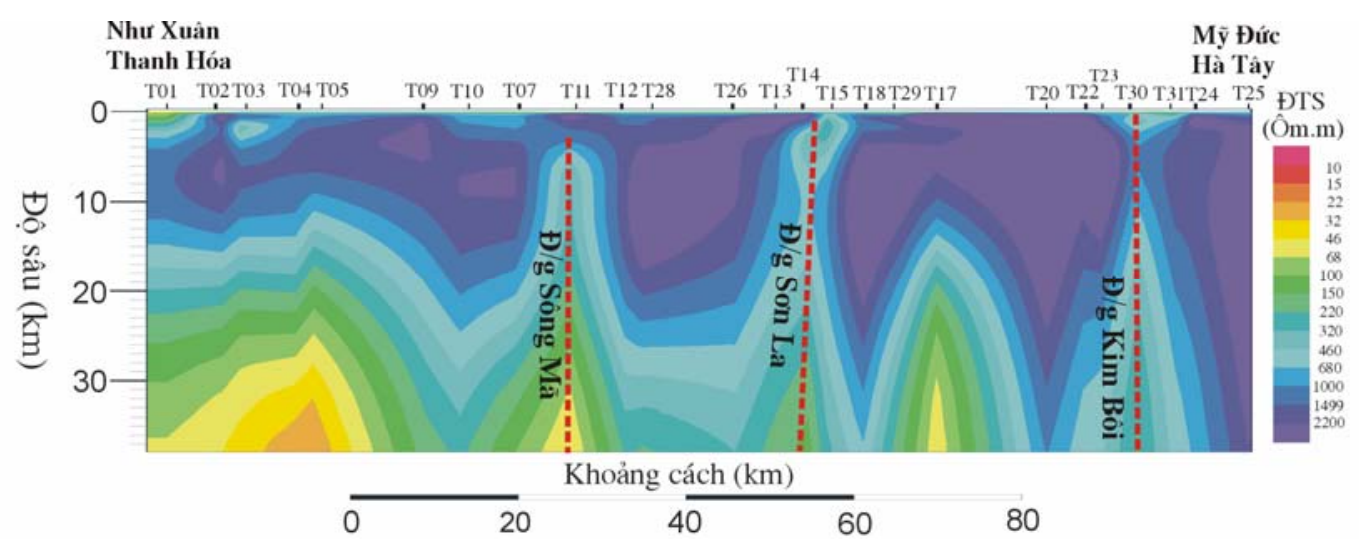

Hình 8. Mặt cắt địa điện tuyến Thanh Hóa-Hà Tây, nghịch đảo 2D thành phần EW

Trên tuyến TH-HT, đứt gãy sông Mã, đứt gãy Sơn $\mathrm{La}$ và đứt gãy Kim Bôi cũng được thể hiện bằng đới có điện trở suất thay đổi khá rõ rệt. Trên mặt cắt địa điện của cả hai tuyến, điện trở suất của vỏ Trái đất thay đổi liên tục từ vài chục $\Omega . m$ tới hàng ngàn $\Omega . \mathrm{m}$. Có một xu thế chung ở cả hai tuyến là phần dưới của mặt cắt, ở độ sâu dưới khoảng $20 \mathrm{~km}$ điện trở suất nhỏ hơn phần bên trên. Phần phía trên ở độ sâu nhỏ hơn khoảng $5 \mathrm{~km}$ điện trở suất cũng nhỏ hơn phần bên dưới. Kiểu cấu trúc vỏ có lớp vỏ bên trên và lớp vỏ bên dưới nhỏ hơn lớp vỏ giữa được gọi là cấu trúc vỏ Phanerozoi, 
kiểu trúc vỏ phổ biến quan sát được ở nhiều vùng trên thế giới $[3,9]$. Ở kiểu cấu trúc vỏ này việc xác định ranh giới Moho từ tài liệu từ telua sẽ khó khăn vì sự chênh lệch điện trở suất giữa Manti và lớp vỏ bên dưới kém rõ rệt, thông tin về mặt Moho chỉ có thể thu được một cách tin cậy từ phân tích số liệu địa chấn dò sâu. Trong các mặt cắt địa điện ở hình 7 và hình 8 dựa vào hình thái biến đổi của điện trở suất theo chiều sâu ở vị trí đứt gãy, chúng tôi giả định rằng các đứt gãy đã nêu (Mường $\mathrm{La}$ - Bắc Yên, sông Hồng, sông Chảy, sông Lô, sông Mã, Sơn La, Kim Bôi) là những đứt gãy sâu xuyên vỏ, tuy nhiên điều này cũng còn mang tính chủ quan, chưa có kết quả đo sâu từ telua bằng các thiết bị khác hiện đại hơn để so sánh.

Cùng với việc nghịch đảo $2 \mathrm{D}$ chúng tôi cũng tiến hành việc nghịch đảo $1 \mathrm{D}$ số liệu thu được tại các điểm đo đã nêu. Để xây dựng mô hình địa điện bằng minh giải $1 \mathrm{D}$ chúng tôi sử dụng phương pháp thử và lựa chọn. Tuy nhiên như chúng ta biết bài toán $1 \mathrm{D}$ cho kết quả đa nghiệm, do vậy người ta phải có thông tin bổ sung để loại đi tính đa nghiệm, ở đây kết quả xác định các ranh giới chính trong vỏ Trái Đất nhờ phương pháp dò sâu địa chấn trên các tuyến đã được sử dụng. Trên tuyến HB-TN, ranh giới giữa lớp vỏ trên và lớp vỏ giữa thay đổi trong khoảng $1-4 \mathrm{~km}$, ranh giới giữa lớp vỏ giữa và lớp vỏ dưới ở độ sâu $14-17 \mathrm{~km}$, mặt Moho ở độ sâu trong khoảng $30-32 \mathrm{~km}$. Trên tuyến TH-HT, các ranh giới tương ứng là $3-4 \mathrm{~km}, 14-17 \mathrm{~km}$ và khoảng $32-37 \mathrm{~km}$. Kết quả nghịch đảo $1 \mathrm{D}$ bằng phương pháp thử và lựa chọn với các độ sâu tham khảo nêu trên từ số liệu địa chấn được trình bày trên hình 9 và hình 10 (đối với tuyến $\mathrm{HB}-\mathrm{TN}$ ), hình 11 và hình 12 (đối với tuyến TH-HT).

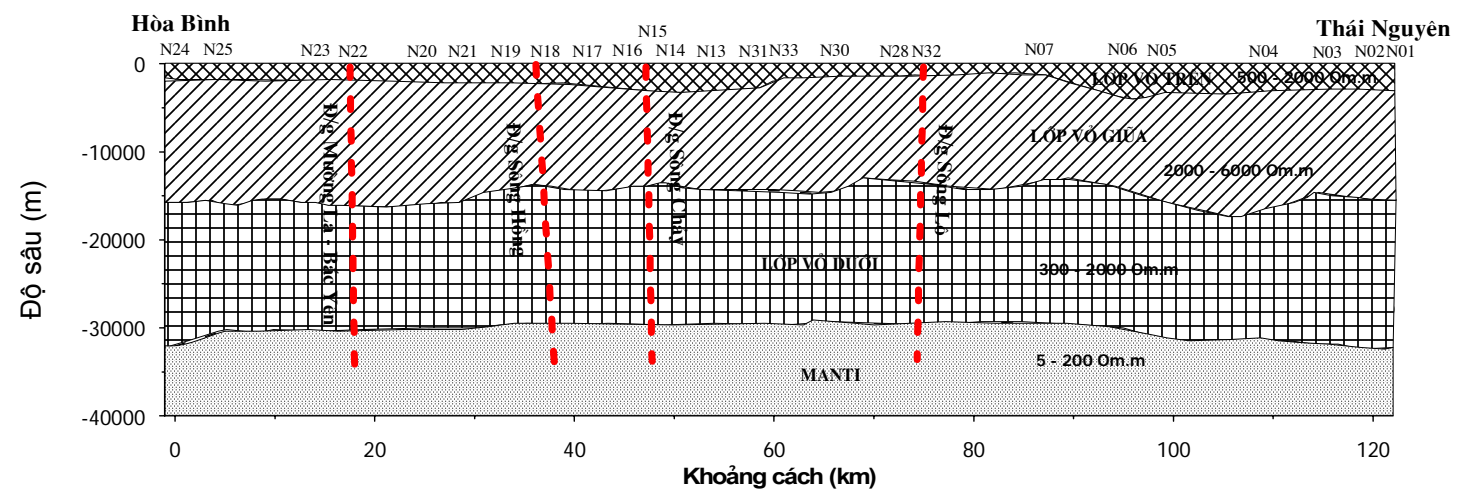

Hình 9. Mặt địa điện tuyến Hòa Bình - Thái Nguyên, nghịch đảo $1 \mathrm{D}$ bằng phương pháp thử và lựa chọn

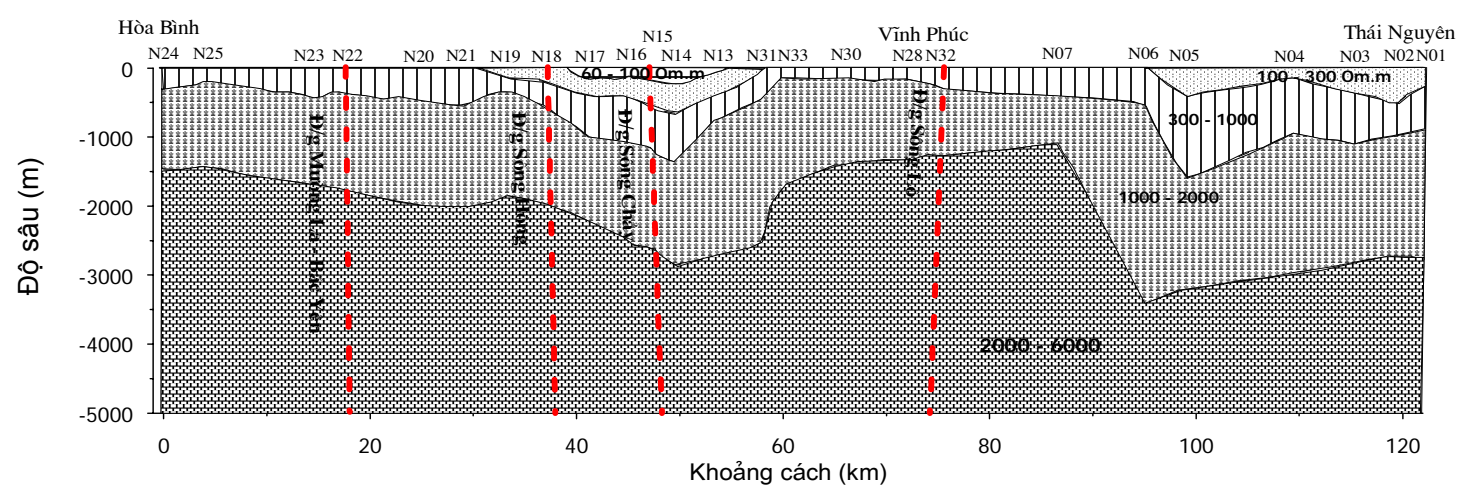

Hình 10. Mặt địa điện tuyến Hòa Bình - Thái Nguyên ở khoảng 5 km đầu tiên, nghịch đảo 1D bằng phương pháp thử và lựa chọn

Hình 9 chỉ ra rằng lớp vỏ bên dưới ở phần lớn các điểm có điện trở suất từ $300 \Omega . m$ đến $2000 \Omega$.m thấp hơn hẳn lớp vỏ giữa có điện trở suất từ $2000 \Omega$.m đến $6000 \Omega$.m, và cao hơn điện trở suất của manti từ $5 \Omega . m$ đến $200 \Omega$.m. Lớp vỏ bên trên ở phần lớn các điểm đều có điện trở suất thấp hơn lớp vỏ giữa. Kết quả phân tích thu được trên hình 9 tương đối phù hợp với kết quả phân tích số liệu đo 
sâu từ telua ở vùng trũng Hà Nội trên các tuyến Ba Vì - Bắc Ninh và Thanh Sơn - Thái Nguyên [9, 10]. Trên hình 9 vị trí các đứt gãy được xác định từ kết quả nghịch đảo 2D tương ứng đã nêu ở hình 7 . Hình 10 biểu diễn mặt cắt địa điện chi tiết của hình 9 đến độ sâu $5 \mathrm{~km}$. Có thể thấy rằng lớp điện trở

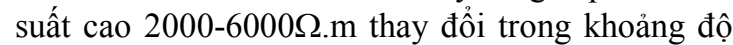
sâu từ $1500 \mathrm{~m}$ ở khu vực Hòa Bình đến gần $3000 \mathrm{~m}$ ở khu vực Thái Nguyên, phần giữa tuyến ở khu vực Vĩnh Phúc lớp điện trở suất cao này nhô lên cao đạt tới độ sâu khoảng $1000 \mathrm{~m}$, điều này có thể do độ dày của tầng trầm tích bên trên ở khu vực đới đứt gãy sông Hồng và phía Thái Nguyên dày hơn ở khu vực Vĩnh Phúc, trong khu vực đới đứt gãy sông Hồng còn có lớp điện trở suất cỡ vài chục $\Omega$.m ở phần trên cùng của mặt cắt, kiểu cấu trúc như vậy phù hợp với kiểu cấu trúc của bồn trũng sông Hồng như đã nêu trong [6].

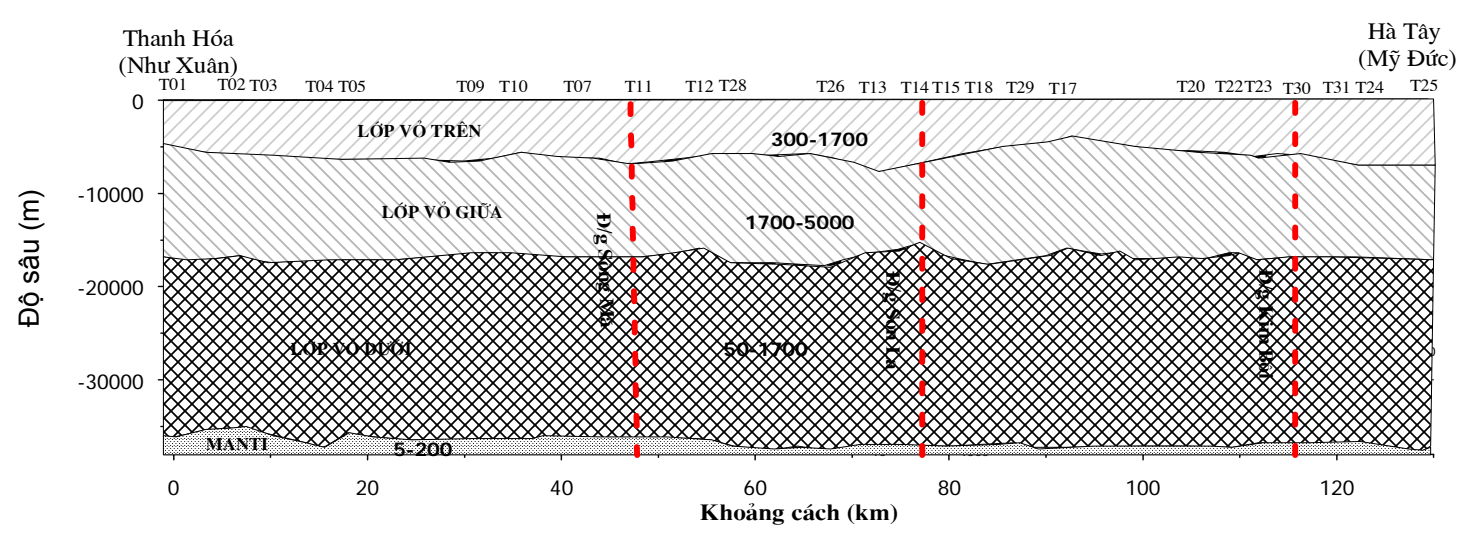

Hình 11. Mặt địa điện tuyến Thanh Hóa-Hà Tây, nghịch đảo $1 \mathrm{D}$ bằng phương pháp thử và lựa chọn.

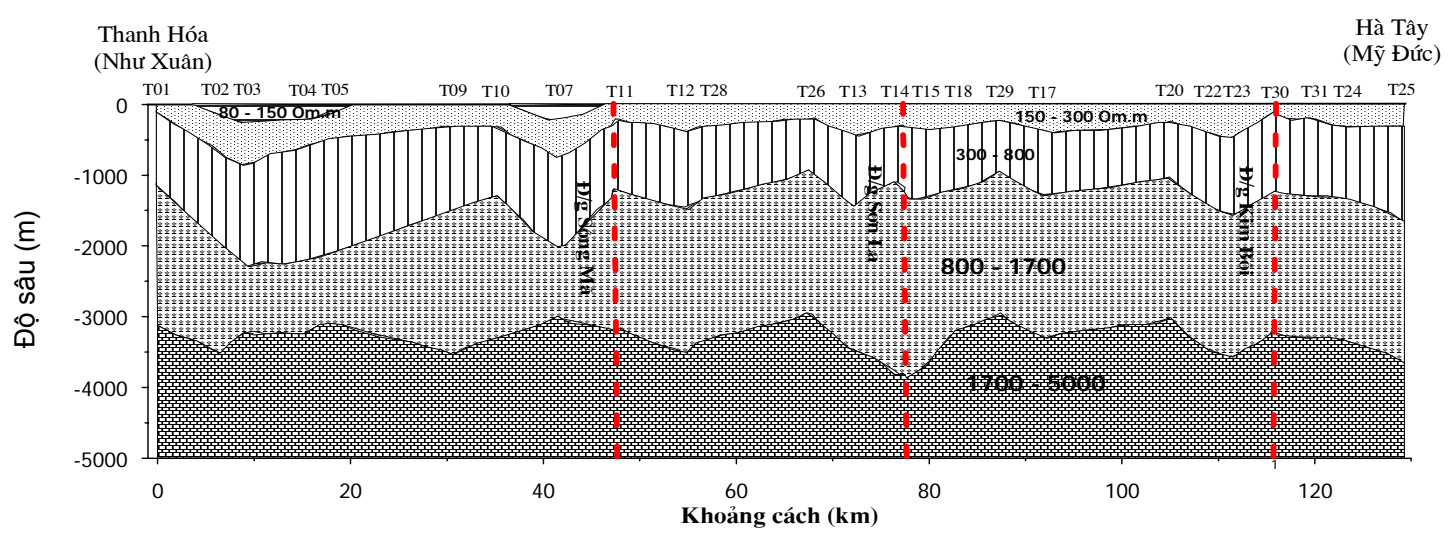

Hình 12. Mặt địa điện tuyến Thanh Hóa - Hà Tây ở khoảng $5 \mathrm{~km}$ đầu tiên, nghịch đảo $1 \mathrm{D}$ bằng phương pháp thử và lựa chọn

Mặt cắt địa điện đối với tuyến TH-HT trên hình 11 cũng cho thấy rằng lớp vỏ bên dưới có điện trở suất từ $50 \Omega . m$ đến $1700 \Omega . m$ thấp hơn lớp vỏ giữa có điện trở suất từ $1700 \Omega . m$ đến $5000 \Omega$.m, và cao

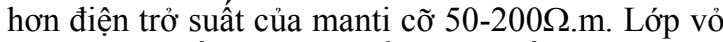
bên trên ở phần lớn các điểm cũng đều có điện trở suất thấp hơn lớp vỏ giữa như ở tuyến HB-TN. Mặt cắt địa điện chi tiết đến độ sâu $5 \mathrm{~km}$ của tuyến THHT trên hình 11 cho thấy lớp có điện trở suất cao 1700-5000 $\Omega . m$ nằm ở độ sâu khoảng $3500 \mathrm{~m}$ có những thay đổi có tính cục bộ trong khoảng vài trăm mét; ranh giới các lớp điện trở suất thấp hơn ở phía trên cũng biến đổi tương tự.

Như vậy qua phân tích ở trên ta thấy đặc điểm về cấu trúc vỏ trên hai tuyến $\mathrm{HB}-\mathrm{TN}$ và $\mathrm{TH}-\mathrm{HT}$ ở kết quả nghịch đảo $1 \mathrm{D}$ có sự tương tự nhau, nhưng dải biến đổi của điện trở suất trong các lớp ở hai tuyến có khác nhau. Điện trở suất lớp vỏ bên dưới thấp hơn lớp vỏ bên trên phù hợp với kết quả nghiên cứu của Đoàn Văn Tuyến và nnk $[11,12]$ ở khu vực đới đứt gãy sông Hồng. 
Như đã nêu thông tin về các ranh giới chính của vỏ Trái đất nhận được từ phân tích số liệu địa chấn thăm dò, hình 9 và 11 cho thấy điện trở suất trong mỗi lớp từ kết quả $1 \mathrm{D}$ biến đổi trong dải khá rộng. Với kết quả phân chia ranh giới như vậy thì sự biến đổi mạnh của điện trở suất trong mỗi lớp cũng thể hiện trên mặt cắt $2 \mathrm{D}$. Điều này có thể hiểu được vì thực tế điện trở suất của đất đá phụ thuộc vào rất nhiều yếu tố, trong đó các yếu tố về hàm lượng chất lỏng, độ khoáng hóa, độ rỗng,... là những yếu tố quan trọng làm điện trở suất của đá có thể giảm mạnh. Tuyến HB-TN cắt ngang qua đới đứt gãy Sông Hồng, trên mặt cắt $2 \mathrm{D}$ cho thấy điện trở suất ở khu vực giữa tuyến từ đứt gãy Mường $\mathrm{La}-\mathrm{Bắc}$ Yên tới đứt gãy sông Lô điện trở suất ở phần vỏ giữa và dưới thấp hơn ở phần đầu (Hòa Bình) và phần cuối tuyến (Thái Nguyên); sự biến đổi theo phương ngang của điện trở suất trong khu vực giữa tuyến cũng rõ rệt hơn. Các vùng điện trở suất cao ở đầu và cuối tuyến $\mathrm{HB}-\mathrm{TN}$ phản ánh rằng cấu trúc của vỏ ở đây rất rắn chắc, trong khi trong khu vực đới đứt gãy Sông Hồng điện trở suất phần vỏ trên và vỏ giữa nhỏ hơn và sự bất đồng nhất theo phương ngang của cấu trúc điện trở là rất rõ ràng, điều này phản ánh mức độ hoạt động kiến tạo mạnh mẽ của đới. Trong các mặt cắt điện trở suất vỏ Trái đất cắt qua các đới đứt gãy $[6,10,11]$, sự tồn tại của lớp vỏ dưới có điện trở suất thấp thường được cho là liên quan với sự chảy dẻo của vật chất dưới tác dụng của nhiệt và nước giải phóng trong quá trình biến chất, hoặc sự nâng lên cục bộ của manti. Trên các mặt cắt điện trở suất ở hình 9 và hình 11 chúng ta có thể thấy điện trở suất lớp vỏ dưới biến đổi từ vài chục $\Omega . \mathrm{m}$ đến hàng ngàn $\Omega . \mathrm{m}$, có nghĩa là sự chảy dẻo chỉ có thể có tính cục bộ lân cận các đứt gãy [4, 5] chứ không thể trong phạm vi toàn bộ lớp vỏ dưới. Như vậy kết quả nghịch đảo $1 \mathrm{D}$ số liệu đo sâu từ telua với thông tin về độ dày các lớp từ số liệu địa chấn cũng khó có thể cho thông tin đầy đủ về trạng thái vật chất của vỏ Trái Đất trên tuyến đo, thông tin như vậy có thể thu được một cách tin cậy hơn từ kết quả nghịch đảo $2 \mathrm{D}$.

\section{Kết luận}

Trong khuôn khổ đề tài "Nghiên cúu cấu trúc sâu thạch quyển miền Bắc Việt Nam bằng dò sâu địa chấn và tù telua nhằm nâng cao độ tin câyy của các dư báo thiên tai địa chất" chúng tôi đã thực hiện đo sâu từ telua trên tuyến Hòa Bình - Thái Nguyên với 33 điểm đo và tuyến Thanh Hóa - Hà
Tây với 31 điểm đo, độ dài của cả hai tuyến khoảng trên $120 \mathrm{~km}$.

Các kết quả nghịch đảo $2 \mathrm{D}$ bằng phương pháp giảm dư nhanh xây dựng được mặt cắt điện trở suất của vỏ Trái Đất cho thấy sự biểu hiện của các đứt gãy lớn trên tuyến HB-TN như đứt gãy Mường La - Bắc Yên, đứt gãy sông Hồng, đứt gãy sông Chảy và đứt gãy sông Lô; trên tuyến TH-HT thể hiện rõ của đứt gãy sông Mã, đứt gãy Sơn La và đứt gãy Kim Bôi; đây là những đứt gãy sâu xuyên vỏ, có hướng cắm gần như thẳng đứng.

Nghịch đảo $1 \mathrm{D}$ bằng phương pháp thử và lựa chọn cho thấy rằng trên cả hai tuyến cấu trúc địa điện của vỏ Trái Đất 3 lớp tiêu biểu, với lớp giữa có điện trở suất cao hơn lớp trên và lớp dưới, lớp Manti có điện trở suất thấp hơn lớp vỏ dưới.

Điện trở suất trong mỗi lớp biến đổi theo phương ngang phụ thuộc vào mức độ hoạt động kiến tạo khu vực; trong đới đứt gãy sông Hồng, điện trở suất của vỏ thấp hơn khu vực lân cận và bất đồng nhất rõ rệt theo phương ngang khẳng định hoạt động kiến tạo mạnh mẽ của đới. Sự giảm điện trở suất rõ rệt lân cận các đứt gãy hoạt động như đứt gãy sông Hồng, đứt gãy sông Chảy, đứt gãy Sơn $\mathrm{La}, \ldots$ được cho là liên quan tới nhiệt và chất lỏng được giải phóng trong quá trình biến chất hoặc sự nâng lên của manti ở lân cận chúng.

Lời cảm ơn: bài báo được hoàn thành trên cơ sở kết quả nghiên cứu của đề tài độc lập cấp Nhà nước "Nghiên cứu cấu trúc sâu thạch quyển miền Bắc Việt Nam bằng dò sâu địa chấn và từ telua nhằm nâng cao độ tin cậy của các dự báo thiên tai địa chất”.

\section{TÀI LIỆU D $\tilde{A N}$}

[1] Cagnia L., 1953: Basic theory of magnetotelluric method of geophysical prospecting, Geophysics, 18, 605-635.

[2] Geotools Corporation, 1997: Geotools MT User's guide.

[3] Jones A., 1992: Electrical conductivity of the continental lower crust, Continental lower Crust, edited by D. M, Fountain, R. J. Arculus and R. W. Kay.

[4] Lê Huy Minh, Võ Thanh Sơn, Nguyễn Chiến Thắng, Nguyễn Trọng Vũ, Nguyễn Đình Xuyên, Guy Marquis, Trần Văn Thắng, 2008: Mặt cắt cấu 
trúc địa điện đới đứt gãy Sơn La theo kết quả đo sâu từ telua, Tạp chí Các khoa học về Trái Đất, T. 30, 4PC, 491-502.

[5] Lê Huy Minh, Phạm Văn Ngọc, Danièle Boyer, Nguyễn Ngọc Thủy, Lê Truòng Thanh, Ngô Văn Quân, Guy Marquis, 2009: Nghiên cứu chi tiết cấu trúc đứt gãy Lai Châu - Điện Biên bằng phương pháp đo sâu từ tellua, Tạp chí Địa chất, loạt A, 311(3-4), 11-21.

[6] Pham V. N., Boyer D., Nguyen Van Giang Nguyen Thi Kim Thoa, 1995: Propriétés électriques et structure profonde de la zone de faille du Fleuve Rouge au Nord Vietnam d'après les résultats de sondage magnéto-tellurique, C. R. Acad. Sci. Paris, 320, série IIa, 181-187.

[7] Quomarudin M., 1994: Propriétés électriques et structures de la croûte en France, (Programmes Ecors, GPF) d'après les résultats de sondage magnéto-tellurique, Thèse, Université Paris 7.

[8] Smith J. T. \& Booker J. R., 1991: The rapid relaxation inverse for two and three dimensional magnetotelluric data, J. Geophys. Res., 96, NO. B3, 3905-3922.

[9] Touret J. L. R., Marquis G., 1994: Fluides profondes et conductivité électrique de la croûte continentale inférieure, C. R. Acad. Sci. Paris, 318, Série II, 1469-1482.

[10] Đoàn Văn Tuyến, Đinh Văn Toàn, Nguyễn Trong Yêm, Phạm Văn Ngọc, Boyer D., 1999: Đặc điểm cấu trúc sâu đới đứt gãy sông Hồng trên khu vực Tây Bắc vùng trũng Hà Nội theo kết quả phân tích tài liệu từ telua, Tạp chí Các Khoa học về Trái Đất, T. 21, 1, 31-35.

[11] Đoàn Văn Tuyến, Đinh Văn Toàn và Nguyễn Trọng Yêm, 2001: Đặc điểm cấu trúc địa động lực đới đứt gãy sông Hồng trên cơ sở tài liệu từ telua, Tạp chí Địa chất, $\mathbf{A}$ 267, 21-28.

[12] Vozoff K., 1972: The magnetotelluric method in the exploration of sedimentary basin, Geophysics, 37, No 1, 98-141.

\section{SUMMARY}

\section{Preliminary results of processing the sounding magnetotelluric data of Hoa Binh - Thai Nguyen and}

Thanh Hoa - Ha Tay profiles

Two magnetotelluric surveys from Hoa Binh (HB) to Thai Nguyen (TN) and from Thanh Hoa (TH) to Ha Tay (HT) have been carried out. The lengths of these profiles are about more than $120 \mathrm{~km}$ with 33 stations (HB-TN), and with 31 stations (TH-HT). The geoelectrical cross-sections along two profiles obtained by two-dimensional inversion of the magnetotelluric data, recording interval ranges from $10^{-3}$ to $10^{3} \mathrm{~s}$ are presented. It is shown that the main faults such as Muong La-Bac Yen, Red River, Chay River and Lo River on the HB-TN profile; Ma River, Son La and Kim Boi on the THHT one, could be recognized by rapid resistivity changes in the crust resistivity models. They are all trans-crustal deep faults with the vertical or nearly vertical dip. Assuming the Earth crust of three layers: upper, middle and lower with the depths of about $1-4 \mathrm{~km}, 14-17 \mathrm{~km}$ and $30-37 \mathrm{~km}$, respectively, from the seismic exploration data, the 1D geoelectrical models are obtained by using the MT software. It is shown that the middle crust's resistivity is significantly higher than the lower and upper one, but the each layer is not homogeneous conductively. The resistivity decreases clearly in the active fault (Red River, Chat River Lo River...) zones, which could be related to the metamorphism releasing heats and fluids or upwelling of the mantle. 